\title{
Casein Phosphopeptide-Amorphous Calcium Phosphate and Shear Bond Strength of Adhesives to Primary Teeth Enamel
}

\author{
Elham Farokh Gisovar ${ }^{1}$; Nassim Hedayati ${ }^{2, *}$; Niloofar Shadman ; Leila Shafiee ${ }^{1}$

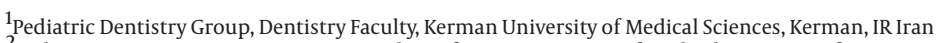 \\ ${ }^{2}$ Pediatric Dentistry Group, Dentistry Faculty, Rafsanjan University of Medical Sciences, Rafsanjan, IR Iran \\ ${ }^{3}$ Restorative and Cosmetic Dentistry Group, Dentistry Faculty, Kerman University of Medical Sciences, IR Iran \\ ${ }^{*}$ Corresponding Author: Nassim Hedayati, Pediatric Dentistry Group, Dentistry Faculty, Rafsanjan University of Medical Sciences, Rafsanjan, IR Iran. Tel: +98-3412119021; +98- \\ 9139873558, E-mail: nassim.hedayati@yahoo.com
}

Received: March 12, 2013; Revised: November 25, 2013; Accepted: November 23, 2014

\begin{abstract}
Background: CPP-ACP (Phosphopeptide-Amorphous Calcium Phosphate) has an important role in caries prevention in pediatric patients. This study was done, because of the great use of CPP-ACP and the need for restoration for teeth treated with CPP-ACP as well as the importance of shear bond strength of adhesives in the success of restorations.

Objectives: This study aimed to evaluate the effect of casein phosphopeptide-amorphous calcium phosphate (CPP-ACP) on shear bond strength of dental adhesives to enamel of primary teeth molars.

Materials and Methods: This in vitro study was conducted on 180 extracted primary molars. They were randomly divided into 6 groups and each group was divided into 2 subgroups (treated with CPP-ACP and untreated). In subgroups with CPP-ACP, enamel was treated with CPP-ACP paste $1 \mathrm{~h} / \mathrm{d}$ for 5 days. Types of adhesives that were evaluated in this study were Tetric N-Bond, AdheSE, AdheSE One F, single Bond 2, SE Bond, and Adper Prompt L-Pop. Shear bond strength was tested with a universal testing machine and mode of failure was evaluated under stereomicroscope. Data were analyzed by T test, 2-way analysis of variance (ANOVA), Tukey and Fisher exact test using SPSS18. P $<0.05$ was considered as significance level.

Results: Shear bond strengths of different adhesive systems to enamel of primary teeth treated and untreated with CPP-ACP showed no significant difference $(\mathrm{P}>0.05)$. Mode of failure in all groups regardless of $\mathrm{CPP}-\mathrm{ACP}$ administration was mainly adhesive type. Our results indicated that CPP-ACP did not affect shear bond strength of studied adhesives to primary teeth enamel.

Conclusions: To have a successful and durable composite restoration, having a high strength bonding is essential. Considering the wide use of CPP-ACP in preventing tooth decay and the role of adhesive shear bond strength (SBS) in success of composite restoration, we conducted the present study to evaluate the effect of CPP-ACP on the SBS of adhesives to primary teeth enamel.
\end{abstract}

Keywords:CPP-ACP; Bond Strength (BS); Adhesive

\section{Background}

Tooth decay is the most common chronic disease during childhood and adolescence. Considering the high rate of tooth decay in children and its consequences, its prevention and treatment is very important (1). The non-invasive treatment of early decay by remineralization is of high importance in the clinical management of disease. Fluoride ion in the presence of calcium and phosphate ions can help replacement of mineral materials in decay lesions through remineralization process (2). When topical fluoride is used, the availability of calcium and phosphate ions is a limiting factor for remineralization. A calcium-phosphate transporting system along with fluoride treatment can treat early tooth decay. In recent years, a new calcium phosphate remineralization technology based on casein phosphopeptide-amorphous calcium phosphate (CPP-ACP) has been introduced, which complements fluoride effects in reducing tooth decay $(2,3)$.
CPP-ACP is a bioactive substance based on dairy products. It attaches to soft tissue plaque pellicle and hydroxyapatite, transfers calcium and amorphous phosphate to saliva and plaque liquid and acts as a resource for calcium phosphate ions. Calcium phosphate amorphous is biologically active and can release calcium phosphate ions to maintain supersaturation level. Therefore, it reduces demineralization and increases remineralization (4).

Since CPP-ACP has an effective role in reducing dental decay, and safe in case of swallowing by kids under two years old, it is widely used in pediatric dentistry, especially in high risk kids with poor dental hygiene (4). Teeth treated with CPP-ACP may need restoration in the future. Today in dentistry, the request for tooth colored restorations has been increased noticeably. Adhesive systems are available to attach the restorations to dental tissue. The efficiency and quality of adhesive systems is important in producing a stable connection between compos- 
ite and dental structure. Shear bond strength (SBS) is one of the important factors in efficiency and quality of adhesive systems because of its essential role in bonding composite to dental tissue. Inadequate SBS causes early failure of restoration in the face of minimum masticatory forces $(5,6)$.

Considering the extensive use of CPP-ACP, and the probable need for restoration of teeth treated with it, and the role of SBS of adhesives in success of composite restorations, it is necessary to evaluate the effect of CPP-ACP on SBS of adhesive systems. To our knowledge, there is not any study on the relation between CPP-ACP and bond strength of adhesive systems to enamel and dentin in primary teeth and studies on permanent teeth are also limited. Some of the studies on permanent teeth have shown that CPP-ACP has no effect on SBS of adhesives $(7,8)$. While some other studies reported increase in SBS of adhesives (9) and other studies reported decrease in SBS (10).

\section{Objectives}

This study was conducted with the aim of assessing the effect of CPP-ACP on the shear bond strength of 6 following adhesive systems to the enamel of primary teeth: Tetric N-Bond (Ivoclar Vivadent, Ets Schaan Liechtenstein), Single Bond 2 (3M, ESPE, St.Paul, MN, USA) from fifth generation, AdheSE (Ivoclar Vivadent, Ets Schaan Liechtenstein), SE Bond (Kurary, Tokyo, Japan) from sixth generation, Adper Prompt L-Pop (3M, ESPE, St.Paul, MN, USA), and AdheSE One F (Ivoclar Vivadent, Ets Schaan Liechtenstein) from seventh generation.

\section{Materials and Methods}

This experimental study was conducted on 180 extracted first and second primary molars, which had intact buccal and lingual surfaces. For sample size calculation, Stata 10 was used.

sampsi 24.319.9, sd1 (4) sd2 (4), power (80)

Estimated sample size for two-sample comparison of means

Test Ho: $m 1=m 2$, where $m 1$ is the mean in population 1 and $\mathrm{m} 2$ is the mean in population 2 ,

Assumptions:

Alpha $=0.0500$ (two-sided)

Power $=0.8000$

$\mathrm{m} 1=24.3, \mathrm{~m} 2=19.9, \mathrm{sd} 1=4, \mathrm{sd} 2=4, \mathrm{n} 2 / \mathrm{n} 1=1.00$

Estimated required sample sizes:

$\mathrm{n} 1=13, \mathrm{n} 2=13$

$$
n=n^{900 ;} \sqrt{g^{1}-1}
$$

$$
n=13 \sqrt{6-1}=30
$$

The inclusion criteria were primary first and second molars with no caries, cracks, or defects on tooth surfaces.
Teeth not having the mentioned criteria were excluded from the study. One thousand extracted teeth were gathered from dental clinics in Kerman City, Iran in 2013. Seven hundred and twenty-three teeth were excluded due to our exclusion criteria. A total of 180 extracted teeth were selected randomly (simple randomization) among the 277 teeth, which had our inclusion criteria. The teeth were randomly (simple randomization) divided into 6 groups (A to $\mathrm{F}, \mathrm{n}=30$ each group representing one adhesive system); each group was divided into 2 subgroups with and without CPP-ACP application.

Remained supportive tissues were removed from the teeth. Then, they were kept in chloramine-B 1\% solution for 24 hours. Next, they were placed in water at room temperature. Using a diamond fissure bur 008 (Tizcavan, Iran), buccal or lingual enamel surfaces were freshened under cold water to reach a smooth surface. The teeth were mounted in self Cure acrylic resin (Acropars, Iran) up to CEJ region, with the help of a surveyor vertical bar so that enamel smooth surfaces were placed perpendicular to the horizon.

In subgroups with CPP-ACP, a small amount of GC Tooth Mousse (GC Corporation, Tokyo, Japan) was placed on the smooth surface of enamel with a mouth spatula for one hour, then the paste was washed for 10 seconds, and tooth was stored in incubator at $37^{\circ}$ under $100 \%$ humidity. This cycle was repeated for five days and then composite was bonded and adhered as explained below.

Group A: The enamel was etched with phosphoric acid $35 \%$ for 20 seconds and then it was washed for 30 seconds and dried with air pressure. An adhesive layer Tetric N-Bond (Ivoclar Vivadent, Ets Schaan, Liechtensteien) was applied on enamel for 10 seconds, was thinned with air pressure and then cured with light curing machine Quartz-Tungsten-Halogen Coltolux75 (Coltene Whale dent, USA) with the intensity of $600 \mathrm{~mW} / \mathrm{cm}^{2}$ for 10 seconds. The intensity of the curing machine was measured and assessed periodically with radiometer (Optilux, SdS, Kerr).

Group B: Adhesive primer AdheSE (Ivoclar Vivadent, Ets Schaan, Liechtenstein) was applied on enamel for 30 seconds, and its excess was thinned with strong pressure of air, then adhesive AdheSE was placed on enamel surface, scattered with weak pressure of air, and was cured for 10 seconds.

Group C: AdheSE One F adhesive was applied on enamel surface for 20 seconds, then with strong pressure of air its excess was removed, and finally it was cured for $10 \mathrm{sec}-$ onds.

Group D: the enamel was etched by phosphoric acid $35 \%$ for 15 seconds, then washed for 10 seconds, and dried. Then, 2-3 adhesive layers of Single Bond 2 (3M, ESPE, St. Paul, MN, USA) were immediately applied on enamel for 15 seconds. Weak air pressure was applied and bonding was cured for 10 seconds.

Group E: Primer SE Bond (Kurary, Tokyo, Japan) was applied on the enamel surface for 20 seconds, and dried with mild air pressure. Then, SE Bond adhesive was 
placed on the enamel surface and thinned with air pressure. Finally, it was cured for 10 seconds.

Group F: Samples were dried gently. The combination of two parts of the adhesive Adper Prompt L-Pop (3M, ESPE, and St. Paul, MN, USA), which was uni-does type was applied with brush on the enamel for 15 seconds. Then it was dried with air pressure slowly, and was cured with light cure machine for 10 seconds.

Z250 composite (3M, ESPE, St. Paul, MN, USA), A1 color was applied on enamel in two layers using clear plastic cylindrical mold with inside diameter of $2 \mathrm{~mm}$ and height of $3 \mathrm{~mm}$. Each layer was cured for 20 seconds. Then plastic mold was removed and composite was cured for another 40 seconds. The samples were stored at $37^{\circ} \mathrm{C}$ water and then thermocycled (500 cycles between $5-55^{\circ} \mathrm{C}$ with a 30 seconds dwell time and a transfer time of 10 seconds) with a thermocycling machine (Baradaran poya, Iran).

To measure the SBS, Testomeric machine (Testomeric, M350-10CT England) was used after calibration. The samples were placed in the way that the bonding surface of tooth was parallel to the device blade. The blade was positioned between composite and enamel, and force was applied to the sample with the speed of $0.5 \mathrm{~mm} / \mathrm{min}$ and with the load cell of $50 \mathrm{kgf}$. When the break occurred, the force amount was documented. The SBS was first calculated in Newton then it was converted to megapascal (Mpa) with the following formula:

Peak load in break zone (Newton)/bond surface $\left(\mathrm{mm}^{2}\right)$. Mode of failure of each sample was observed with stereomicroscope (Olympus, DP12, Germany) with $40 \times$ enlargement. Each sample was observed by two educated observ- ers. $\kappa$ coefficient for agreement of the two observers was 0.80 . The modes of failure were classified as follows:

- Cohesive failure in enamel

- Adhesive failure between enamel and adhesive or between adhesive and composite (in dental-composite interface zone)

- Cohesive failure in composite

- Mixed failure (display of adhesive and cohesive failures together)

This study was done on extracted primary molars so the ethical considerations were considered in our study. Accuracy and honesty in reporting were also considered in this study. Adhesives used and application of CPP-ACP were the independent variables and shear bond strength and the mode of failure were dependent variables.

SPSS V18 was used to evaluate and analyze the data. The significant level was considered 0.05 in all calculations. For the assessment of "Mode of failure", Fisher exact test was used. For analyzing other variables after checking the normality of the data with Kolmogorov-Smirnov test, 2-way ANOVA, Tukey, and HSD were used. T test was used for the comparison of shear bond strength of each adhesive in the condition of CPP-ACP application and without application.

\section{Results}

The shear bond strength of the study groups are demonstrated in Table 1. Shear bond strength of Tetric NBond, AdheSE, AdheSE One F, Single Bond 2, SE Bond, and Adper Prompt L-Pop did not show statistically significant differences with or without CPP-ACP application (Table 1).

Table 1. The Shear Bond Strength in Tetric N-bond, Single Bond 2, SE Bond, AdheSE, AdheSE One F, Adper Prompt L-Pop Groups, With and Without CPP-ACP Application ${ }^{\text {a }}$

\begin{tabular}{|c|c|c|c|}
\hline Group & No., $n=138$ & Deviation, Mpa & P Value \\
\hline Tetric N-Bond & & & 0.392 \\
\hline Without CPP-ACP & 12 & $23.3625 \pm 3.65971$ & \\
\hline With CPP-ACP & 12 & $22.1308 \pm 3.24283$ & \\
\hline AdheSE & & & 0.947 \\
\hline Without CPP-ACP & 11 & $17.5409 \pm 2.84244$ & \\
\hline With CPP-ACP & 13 & $17.4669 \pm 2.53758$ & \\
\hline AdheSE OneF & & & 0.206 \\
\hline Without CPP-ACP & 11 & $17.6955 \pm 3.04133$ & \\
\hline With CPP-ACP & 11 & $16.2073 \pm 2.23079$ & \\
\hline Single Bond 2 & & & 0.426 \\
\hline Without CPP-ACP & 12 & $21.5475 \pm 2.21732$ & \\
\hline With CPP-ACP & 12 & $20.4567 \pm 3.57569$ & \\
\hline SE Bond & & & 0.597 \\
\hline Without CPP-ACP & 11 & $18.8191 \pm 4.26039$ & \\
\hline With CPP-ACP & 11 & $17.8800 \pm 3.84904$ & \\
\hline Adper Prompt L-Pop & & & 0.69 \\
\hline Without CPP-ACP & 11 & $17.3955 \pm 3.29757$ & \\
\hline With CPP-ACP & 12 & $16.8575 \pm 3.37304$ & \\
\hline
\end{tabular}


Farokh Gisovar E et al.

Table 2. Failure Pattern of Tetric N-Bond, Single Bond 2, SE Bond, AdheSE, AdheSE One F, Adper Prompt L-Pop to Primary Teeth Enamel With and Without CPP-ACP Application

\begin{tabular}{|c|c|c|c|c|}
\hline \multirow[t]{2}{*}{ Bonding } & \multicolumn{4}{|c|}{ Mode of Failure } \\
\hline & Cohesive Enamel & Cohesive Composite & Adhesive & Mixed \\
\hline \multicolumn{5}{|l|}{ Tetric N-Bond } \\
\hline Without CPP-ACP & $1(8.3)$ & $0(0)$ & $7(58.3)$ & $4(33.3)$ \\
\hline With CPP-ACP & $2(16.7)$ & $0(0)$ & $7(58.3)$ & $3(25.0)$ \\
\hline \multicolumn{5}{|l|}{ AdheSE } \\
\hline Without CPP-ACP & $0(0)$ & $0(0)$ & $9(81.8)$ & $2(18.2)$ \\
\hline With CPP-ACP & $2(15.4)$ & $0(0)$ & $9(69.2)$ & $2(15.4)$ \\
\hline \multicolumn{5}{|l|}{ AdheSE One F } \\
\hline Without CPP-ACP & $0(0)$ & $0(0)$ & $8(72.7)$ & $3(27.3)$ \\
\hline With CPP-ACP & $1(9.1)$ & $0(0)$ & $10(90.9)$ & $0(0)$ \\
\hline \multicolumn{5}{|l|}{ Single Bond 2} \\
\hline Without CPP-АCP & $0(0)$ & $0(0)$ & $7(58.3)$ & $5(41.7)$ \\
\hline With CPP-ACP & $2(16.7)$ & $0(0)$ & $6(50.0)$ & $4(33.3)$ \\
\hline \multicolumn{5}{|l|}{ SE Bond } \\
\hline Without CPP-ACP & $2(18.2)$ & $0(0)$ & $8(72.7)$ & $1(9.1)$ \\
\hline With CPP-ACP & $1(9.1)$ & $0(0)$ & $8(72.7)$ & $2(18.2)$ \\
\hline \multicolumn{5}{|c|}{ Adper Prompt L-Pop } \\
\hline Without CPP-АCP & $0(0)$ & $0(0)$ & $11(100)$ & $0(0)$ \\
\hline With CPP-ACP & $1(8.3)$ & $0(0)$ & $10(83.3)$ & $1(8.3)$ \\
\hline
\end{tabular}

In the groups with CPP-ACP application, the shear bond strength of the different adhesive systems was compared with 2-way ANOVA, which was significantly different (P $=0.000)$. Afterwards the shear bond strength of the adhesive systems was compared two by two using Tukey test. The shear bond strength of Tetric N-Bond (22.13 \pm 3.24Mpa) was significantly higher than AdheSE (17.46 \pm 2.53 , Mpa $)(\mathrm{P}<0.05)$. The shear bond strength of Tetric $\mathrm{N}$ Bond was significantly higher than AdheSE One F (16.20 \pm 2.23 , Mpa $)(\mathrm{P}<0.05)$, also the shear bond strength of Tetric N-Bond (22.13 \pm 3.24 , Mpa) was significantly higher than SE Bond $(17.88 \pm 3.84, \mathrm{Mpa})(\mathrm{P}<0.05)$. The shear bond strength of Tetric N-Bond (22.13 \pm 3.24 , Mpa) and Adper Prompt L-Pop (16.85 \pm 3.37 , Mpa) differed significantly (P $<0.05)$. The shear bond strength of Single Bond 2 (20.45 \pm 3.57 , Mpa) was significantly higher than AdheSE (17.46 \pm 2.53 , Mpa $)(\mathrm{P}<0.05)$. The shear bond strength of Single Bond $2(20.45 \pm 3.57$, Mpa) and AdheSE (17.46 \pm 2.53 , Mpa) differed significantly $(\mathrm{P}<0.05)$. Differences among Single Bond 2 (20.45 $\pm 3.57, \mathrm{Mpa})$ and AdheSE One F (16.20 \pm 21.23 , Mpa), also Single Bond 2(20.45 \pm 3.57 , Mpa) and Adper Prompt L-Pop $(16.85 \pm 3.37$, Mpa) was significant $(\mathrm{P}<0.05)$. The mode of failure of the adhesive systems to primary teeth enamel with and without CPP-ACP application is presented in Table 2. For the assessment of 'Mode of failure,' Fisher exact test was used. The mode of failure was not statistically significant among groups $(\mathrm{P}>0.05)$
(Table 2). The most common mode of failure among all groups was adhesive (Table 2 ).

\section{Discussion}

To have a successful and durable composite restoration, a strong bonding is essential. Considering the wide use of CPP-ACP in preventing tooth decay and the role of adhesive shear bond strength in the success of composite restoration, we conducted the present study to evaluate the effect of CPP-ACP on the SBS of adhesives to primary teeth enamel. To our knowledge, there was no study so far evaluating the effect of CPP-ACP on the SBS of adhesives to primary teeth enamel.

Adhesive systems are classified into two groups: etchand-rinse and self-etching adhesives (11). In this study, Tetric N-Bond and Single Bond 2 adhesives are etch-andrinse adhesives, and AdheSE, AdheSE One F, SE Bond, and Adper Prompt L-Pop adhesives are self-etching adhesive.

\subsection{The Effect of CPP-ACP Application on Shear Bond Strength of Etch-and-Rinse Adhesive Systems}

The SBS of Tetric N-Bond and Single Bond 2 to enamel with and without CPP-ACP application did not show significant difference. Shadman et al. studied the effect of CPP-ACP on the SBS of Tetric N-Bond adhesive to enamel and found no significant effect. Acid phosphoric $(\mathrm{pH}=$ 
0.5) has strong etching property in removing calcium and phosphate from enamel surface, increasing available surface for bonding, and increasing free energy of the enamel surface was the reason mentioned in their study. Eliminating contaminations from enamel surface with washing and providing a clean surface for bonding, was proposed as another reason in this study (9). Moule et al. showed that CPP-ACP does not affect the SBS of Single Bond adhesive to permanent tooth (12). Other studies, which evaluated CPP-ACP effects on SBS of total etch adhesives to enamel showed similar results $(8,13,14)$. Adebayo et al. also showed that CPP-ACP did not increase SBS of Single Bond adhesive to permanent teeth enamel (7).

The study of Adebayo et al. which evaluated teeth enamel by SEM (Scanning Electron Microscope) after CPP-ACP application showed that CPP-ACP is unable to prevent or interfere with enamel etching by acid phosphoric. Acid phosphoric removes calcium from enamel surface, increases enamel surface for adhesion, and changes enamel smooth surface to a rough surface with high free surface energy. When etching material is washed away from enamel, surface contaminations will be removed from enamel surface so that a clean surface for bonding is achieved. Acid phosphoric is able to clean enamel surface contaminations (15).

\subsection{Effect of CРP-ACP Application on Shear Bond Strength of Self-Etch Adhesive Systems}

In the present study, the effect of CPP-ACP application on SBS of SE Bond adhesive to primary teeth enamel was evaluated and no significant effect was seen. In the study of Adebayo, CPP-ACP did not affect micro-shear bond strength of SE Bond adhesive to permanent teeth enamel (7). Oskoee et al. also showed that CPP-ACP did not affect the SBS of SE Bond to permanent teeth enamel (16). Moule et al. study indicated the significant decrease of the SBS of SE Bond adhesion to permanent teeth enamel by applying CPP-ACP. Moule explained that teeth treated with CPP-ACP are more resistant to acid, and the reduction in SBS may be due to the inability of self-etch adhesives in etching acid resistant enamel. In addition, it is possible that some of the CPP-ACP complex remains as surface contamination on enamel, not eliminated by washing and may interfere with bonding (12).

In SEM evaluation by Adebayo et al. on the enamel of permanent teeth, enamel had smooth surface with little pitting. When SE Bond was used, more pitting was observed with minimum loss of enamel surface, but typical etching pattern was not observed. Enamel surface with and without CPP-ACP application showed little difference. When SE Bond primer was used in surface treated with CPP-ACP, rougher surface was seen compared to non-treated surface with no sign of specific etching pattern. Generally, the morphology of resin-enamel interface with or without CPP-ACP application is the same (7).

In this study, CPP-ACP did not have any effect on the shear bond strength of AdheSE adhesive to primary tooth enamel, which is similar to some other studies. Zorba et al. that studied the effect of Tooth Mousse on SBS of adhesives to permanent tooth dentin did not report any significant difference in SBS of AdheSE with or without CPP-ACP application (17). Oskoee study also showed that CPP-ACP did not significantly affect SBS of AdheSE adhesive to permanent tooth enamel (16). However in Uysal study, CPP-ACP significantly reduced SBS of AdheSE adhesive to permanent tooth enamel. Increased enamel resistance to acidic attack and less adhesive penetration in enamel caused by the remaining of CPP-ACP paste, which is not eliminated properly with self-etch adhesive were the reasons for this reduction (9).

In our study, the SBS of AdheSE One F to enamel of primary tooth did not show difference with and without CPP-ACP application. In Shadman et al. study, SBS of AdheSE One $\mathrm{F}$ to permanent teeth enamel reduced when CPP-ACP was used. The reason was explained as CPP-ACP application provides a hypermineralized enamel surface, which reduces self-etch primer etching effect with weak acidic property on this surface, and changes resin penetration and resin tags formation. Remaining residuals of paste inside pores of enamel surface that primer is not able to remove or penetrate through it are also responsible for the findings (27). This study was conducted on permanent teeth, while we studied primary teeth.

Our results also showed that SBS of adhesive Adper Prompt L-Pop to primary teeth enamel did not significantly differ with or without using CPP-ACP. We did not find any study on the effect of CPP-ACP on the SBS of Adper Prompt L-Pop to permanent or primary teeth enamel, but in Zorba's study who evaluated Tooth Mousse effects on SBS of adhesives to dentin, no significant difference was observed with and without Tooth Mousse. It was reported in the study that CPP-ACP blocks teeth dentin tubules and reduces dentin hypersensitivity. The reduced permeability may decrease bond strength, but it has different effects on different adhesive systems (17).

In the present study, CPP-ACP application did not significantly change the SBS of studied adhesiveness to primary tooth enamel. In microscopic evaluation that had been done in Adebayo study, the enamel surface show little difference with and without CPP-ACP application; etching pattern and morphology of resin-enamel interface were also similar in both situations (15).

\subsection{Effect of СРP-ACP Application on Failure Mode}

In our study, the dominant failure pattern among all groups was adhesive type, and difference between groups regarding failure pattern were not significant. Gateva et al. reported that in adhesive systems with less bond strength, failure pattern is mainly adhesive, while cohesive and mix patterns occur in systems with stronger bonds (18). Perdigao et al. reported that when bond strength is more than $17.40 \mathrm{Mp}$, the cohesive failure pattern starts to appear (19). However some other stud- 
ies stated that failure pattern is not related to the bond strength $(20,21)$.

The two by two group comparison of the SBS of etch-andrinse adhesives together and self-etch adhesive together in the condition of CPP-ACP application were performed and showed no significant difference. In the condition of CPP-ACP application, the SBS of etch-and-rinse adhesives compared with self-etch adhesives in two by two comparisons were significantly higher except for Single Bond 2 and SE Bond. This result may be related to the stronger effect of phosphoric acid in removing calcium and phosphate from enamel surface compared with self-etch primers, and also better removal of CPP-ACP paste from enamel surface when etchant is used, which cause better monomer penetration to enamel (7).

Acid etch removes $10 \mu \mathrm{m}$ of enamel surface and induces a porous surface. When resin material with its flow property is applied on the etched surface, it penetrates and microscopic tags form. Macro tags will form between enamel prism rods, and micro tag forms in central part of the enamel prism body. The prism-less external layer is more common in primary teeth compared to permanent teeth. Enamel prisms are not present in this layer and this layer has a high mineral content. Less specific etch pattern occurs in this layer, which causes less resin penetration. Self-etch systems have lesser acidic property compared to phosphoric acid and cannot remove this layer properly, therefore a shallow etch pattern is created and adhesives penetrate less into the enamel surface (22).

In our evaluation, the SBS of Single bond 2 adhesive compared to SE Bond adhesive in the condition of CPPACP application showed no significant difference. The similar bond strength of SE Bond and Single bond can be explained by extra chemical bond, which is created between enamel hydroxyapatite and 10-MDP (23).

The known important factors in bond strength are $\mathrm{pH}$, type of solvent, functional monomer, and filler content (24). Adper Prompt L-Pop ( $\mathrm{pH}=0.8$ ) has high etching effect and creates etching pattern similar to phosphoric acid. AdheSE $(\mathrm{pH}=1.5)$ and AdheSE One $\mathrm{F}(\mathrm{pH}=1.4)$ have medium etching power and are more acidic compared to SE Bond $(\mathrm{pH}=2)$, therefore create more micromechanical locking in enamel $(24,25)$. SE Bond has MDP monomer, which has potential of bonding to calcium (25). SE Bond solvent is ethanol (26), which has higher steam pressure compared to water, therefore evaporates better with air drying. The solvent in Adper Prompt L-Pop and AdheSE One $\mathrm{F}$ is water and in AdheSE the solvent is water and HEMA $(26,27)$. Despite stronger pH of Adper Prompt LPop, AdheSE One F, and AdheSE, eliminating water excess between tooth and restoration is more difficult when adhesive is used. Water excess reduces adhesive bond strength by forming water blisters. Water excess dilutes primer and reduces its effects (28).

Another important factor in the strength of a bond is filler content (24). AdheSE (contain 2\% filler), AdheSE One $\mathrm{F}$ (contain less than 5\% filler), and SE Bond (contain 10\% filler) are adhesives with fillers $(14,29)$. Resins with fillers have ability to reduce contraction stress. Adhesives containing fillers create thicker layer after air application. The thicker adhesive layer reduces contraction stresses because of higher elasticity. The thicker layer acts as padding during polymerization and somewhat neutralizes forces. Adhesive with fillers also produce less contraction inside themselves (28).

So far, no study has evaluated the effect of CPP-ACP on the shear bond strength of adhesives to the enamel of primary teeth and this study was the first study done on primary teeth. This study evaluated 6 adhesive systems, which was a strong point of this study. This study used the methodology of similar studies $(9,10,12)$, therefore, it is recommended that the methods used for further studies match the real conditions of in vivo environment.

\section{Funding/Support}

This study was supported by Kerman University of Medical Sciences and Tooth and Oral Disease Research Center.

\section{Authors' Contributions}

Study concept and design: Dr Niloofar Shadman; Acquisition of data: Dr Nassim Hedayati; Analysis and interpretation of data: Dr Nassim Hedayati; Drafting of the manuscript: Dr Nassim Hedayati; Critical revision of the manuscript for important intellectual content: Dr Nassim Hedayati and Dr Niloofar Shadman; Statistical analysis, administrative, technical, and material support: Dr Niloofar Shadman, Dr Nassim Hedayati, and Dr Elham Farokh Gisvar; and Study supervision: Dr Niloofar Shadman, Dr Nassim Hedayati, Dr Elham Farokh gisvar, and Dr Leila Shafiee.

\section{References}

1. Koch G, Poulsen S. Pediatric dentistry.Chichester: Wiley Blackwell; 2009.

2. Reynolds EC. Casein phosphopeptide-amorphous calcium phosphate: the scientific evidence. Adv Dent Res. 2009;21(1):25-9.

3. Reynolds EC, Cai F, Cochrane NJ, Shen P, Walker GD, Morgan MV, et al. Fluoride and casein phosphopeptide-amorphous calcium phosphate. J Dent Res. 2008;87(4):344-8.

4. Azarpazhooh A, Limeback H. Clinical efficacy of casein derivatives: a systematic review of the literature. J Am Dent Assoc. 2008;139(7):915-24.

5. Powers JM, Sakaguchi RL. Craig's restorative dental materials, 13/e.: Elsevier India.

6. Van Meerbeek B, De Munck J, Yoshida Y, Inoue S, Vargas M, Vijay $\mathrm{P}$, et al. Buonocore memorial lecture. Adhesion to enamel and dentin: current status and future challenges. Oper Dent. 2003;28(3):215-35.

7. Adebayo OA, Burrow MF, Tyas MJ. Effects of conditioners on microshear bond strength to enamel after carbamide peroxide bleaching and/or casein phosphopeptide-amorphous calcium phosphate (CPP-ACP) treatment. J Dent. 2007;35(11):862-70.

8. Kecik D, Cehreli SB, Sar C, Unver B. Effect of acidulated phosphate fluoride and casein phosphopeptide-amorphous calcium phosphate application on shear bond strength of orthodontic brackets. Angle Orthod. 2008;78(1):129-33.

9. Uysal T, Baysal A, Uysal B, Aydinbelge M,Al-Qunaian T. Do fluoride and casein phosphopeptide-amorphous calcium phosphate af- 
fect shear bond strength of orthodontic brackets bonded to a demineralized enamel surface? Angle Orthod. 2011;81(3):490-5.

10. Khoroushi M, Ghazalgoo A. Effect of desensitizer application on shear bond strength of composite resin to bleached enamel. Indian J Dent Res. 2013;24(1):87-92.

11. Perdigão J, Swift Jr EJ, Roberson TM, Heymann HO, Swift Jr EJ. Fundamental concepts of enamel and dentin adhesion. Sturdevant's Art \& Science of Operative Dentistry. 2002;4:237-68.

12. Moule CA, Angelis F, Kim GH, Le S, Malipatil S, Foo MS, et al. Resin bonding using an all-etch or self-etch adhesive to enamel after carbamide peroxide and/or CPP-ACP treatment. Aust Dent J. 2007;52(2):133-7.

13. Xiaojun D, Jing L, Xuehua G, Hong R, Youcheng Y, Zhangyu G, et al. Effects of CPP-ACP paste on the shear bond strength of orthodontic brackets. Angle Orthod. 2009;79(5):945-50.

14. Cehreli SB, Sar C, Polat-Ozsoy O, Unver B, Ozsoy S. Effects of a fluoride-containing casein phosphopeptide-amorphous calcium phosphate complex on the shear bond strength of orthodontic brackets. Eur J Orthod. 2012;34(2):193-7.

15. Adebayo OA, Burrow MF, Tyas MJ. An SEM evaluation of conditioned and bonded enamel following carbamide peroxide bleaching and casein phosphopeptide-amorphous calcium phosphate (CPP-ACP) treatment. J Dent. 2009;37(4):297-306

16. Oskoee SS, Bahari M, Kimyai S, Navimipour EJ, Firouzmandi M. Shear bond strength of self-etching adhesive systems with different $\mathrm{pH}$ values to bleached and/or CPP-ACP-treated enamel. Adhes Dent. 2012;14(5):447-52.

17. Zorba YO, Erdemir A, Ercan E, Eldeniz AU, Kalaycioglu B, Ulker M. The effects of three different desensitizing agents on the shear bond strength of composite resin bonding agents.J Mech Behav Biomed Mater. 2010;3(5):399-404.

18. Gateva N. Bond strength of self-etch adhesives with primary and permanent teeth dentin - in vitro study. J IMAB. 2012;18, 2(2012):168-73.

19. Perdigao J, May KJ, Wilder AJ, Lopes M. The effect of depth of den- tin demineralization on bond strengths and morphology of the hybrid layer. Oper Dent. 2000;25(3):186-94.

20. Watanabe LG, Marshall GJ, Marshall SJ. Dentin shear strength: effects of tubule orientation and intratooth location. Dent Mater. 1996;12(2):109-15.

21. O'Keefe KL, Pinzon LM, Rivera B, Powers JM. Bond strength of composite to astringent-contaminated dentin using self-etching adhesives. Am J Dent. 2005;18(3):168-72.

22. Endo T, Ozoe R, Shinkai K, Shimomura J, Katoh Y, Shimooka S. Comparison of shear bond strengths of orthodontic brackets bonded to deciduous and permanent teeth. Am J Orthod Dentofacial Orthop. 2008;134(2):198-202.

23. Lopes GC, Marson FC, Vieira LC, de Caldeira AM, Baratieri LN. Composite bond strength to enamel with self-etching primers. Oper Dent. 2004;29(4):424-9.

24. Yazici AR, Yildirim Z, Ertan A, Ozgunaltay G, Dayangac B, Antonson SA, et al. Bond strength of one-step self-etch adhesives and their predecessors to ground versus unground enamel. Eur J Dent. 2012;6(3):280-6.

25. Atash R, Van den Abbeele A. Bond strengths of eight contemporary adhesives to enamel and to dentine: an in vitro study on bovine primary teeth. Int J Paediatr Dent. 2005;15(4):264-73.

26. Miranda C, Prates LH, Vieira Rde S, Calvo MC. Shear bond strength of different adhesive systems to primary dentin and enamel. $J$ Clin Pediatr Dent. 2006;31(1):35-40.

27. Shadman N, Ebrahimi SF, Abrishami A, Sattari H. Shear bond strength of three adhesive systems to enamel and dentin of permanent teeth. J Den Med.2012;25(3):202-10.

28. Van Landuyt KL, Snauwaert J, De Munck J, Peumans M, Yoshida Y, Poitevin A, et al. Systematic review of the chemical composition of contemporary dental adhesives. Biomaterials. 2007;28(26):3757-85.

29. Ardu S, Castioni NV, Benbachir N, Krejci I. Minimally invasive treatment of white spot enamel lesions. Quintessence Int. 2007;38(8):633-6. 